\title{
(2) OPEN ACCESS \\ Prediction of emergency cesarean section by measurable maternal and fetal characteristics
}

\author{
Ping Guan, Fei Tang, Guoqiang Sun, Wei Ren
}

\section{Correspondence to DrWei Ren, Department of Obstetrics, Maternal and Child Health Hospital of Hubei Province, Wuhan, China; \\ touga0201812@163.com}

Accepted 23 October 2019 Published Online First 24 January 2020
Check for updates

(C) American Federation for Medical Research 2020. Re-use permitted under CC BY-NC. No commercial re-use. Published by BMJ.

To cite: Guan P, Tang F, Sun $\mathrm{G}$, et al. J Investig Med 2020;68:799-806.

\begin{abstract}
Objective To analyze the maternal and fetal factors affecting emergency cesarean section (EmCS) and establish a risk scoring system to quantitatively predict the risk of EmCS.

Design A total of 10,295 pregnant women were enrolled in this study. The influence of maternal and fetal factors on the risk of EmCS was analyzed. Results 991 (9.63\%) cases of failed vaginal delivery received EmCS. The two main causes of EmCS were fetal distress (67.21\%) and abnormal fetal position (14.93\%). There were significant differences in 17 maternal and fetal factors between the normal vaginal delivery (NVD) and EmCS groups ( $p<0.05$ for all). Univariate and multivariate regression analyses showed that nine maternal and infant factors were independent risk factors ( $p<0.05$ for all). The major factors were abnormal quantity of amniotic fluid (OR $6.867,95 \% \mathrm{Cl} 4.442$ to 10.618 ), nulliparous (OR $4.336,95 \% \mathrm{Cl} 3.074$ to 6.115), induction of labor (OR 5.300, 95\% Cl 4.514 to 6.224) and abnormal characters of amniotic fluid (OR 3.126, 95\% Cl 2.708 to 3.608). A risk scoring system (six grades) was established based on those factors which showed high discriminative power. The rate of EmCS was $1.30 \%, 2.57 \%, 5.83 \%$, $13.94 \%, 21.75 \%$ and $39.71 \%$ in grades $1,2,3,4$, 5 and 6 , respectively. The area under the curve of the risk scoring system was 0.787 , indicating that the regression model of the risk factors had a good predictive ability.

Conclusion An effective risk scoring system has been developed to quantitatively assess the risk of EmCS based on measurable maternal and fetal factors. The system is simple, easy to operate and has good repeatability in clinical practice.
\end{abstract}

\section{INTRODUCTION}

Although there is major geographic variation in rates and trends over time, with rates declining in some of the largest urban areas, the overall annual rate of cesarean section (CS) has increased in China, reaching 34.9\%. ${ }^{1}$ Such data are comparable to those in the USA, ${ }^{2}$ but more than twice as high as the $10-15 \%$ recommended by the World Health Organization. ${ }^{34}$ This also brings a series of adverse maternal and fetal outcomes caused by CS. ${ }^{5-7}$ Therefore, CS should be done only when there are definite medical indications. However, we have to admit that CS is an effective means to solve the

\section{Significance of this study}

What is already known about this subject?

- Emergency cesarean section (EmCS) can be a life-saving procedure if pregnant women experience abnormal conditions in the process of vaginal delivery.

- Deciding to perform EmCS is a complicated process, occurring only in specific obstetric conditions, and requires awareness and rapid assessment of the risky situation.

\section{What are the new findings?}

- Maternal and fetal factors differ in normal vaginal delivery and EmCS groups, with $>20$ maternal and infant characteristics differing between the two groups.

- About 12 maternal and fetal factors were associated with risk of EmCS.

- A risk scoring system for EmCS based on nine distinct factors that could be determined before delivery has been established with strong objectivity and good repeatability for Chinese women.

\section{Significance of this study}

How might these results change the focus of research or clinical practice?

- In clinical circumstances, the information of factors included in the risk scoring system can be evaluated before delivery. Thus, this risk scoring system is simple, easy to operate and has good repeatability in clinical practice. If the score is too high, we should pay close attention to the situation of mothers and babies should be monitored closely during childbirth.

medical and surgical complications of dystocia and severe complications of pregnancy, and has an irreplaceable role. ${ }^{8}$ Emergency CS (EmCS) can be a life-saving procedure if pregnant women experience abnormal conditions in the process of vaginal delivery such as fetal distress, eclampsia or severe pre-eclampsia. ${ }^{9}$ It has been reported that about $14.9 \%$ of all deliveries are transferred to EmCS during vaginal delivery for identified indications in China. ${ }^{10}$ 
Thus, a trial of labor via the vagina should be carried out for pregnant women without specific indications of CS. At the same time, close attention should be paid to the changes in maternal and fetal health status in order to ensure the safety of mothers and infants, and to prepare for EmCS. Deciding to perform EmCS is a complicated process, occurring only in specific obstetric conditions, and requires awareness and rapid assessment of the risky situation. ${ }^{11}$ Failure to perform EmCS in time may lead to postpartum mental disorders ${ }^{12}$ and even serious adverse maternal and fetal outcomes. ${ }^{13}$ Recognizing an acute situation which may be potentially life-threatening is considered one of the most challenging tasks in obstetrics. ${ }^{14}$ Most studies focus on the related factors and prognosis of elective CS, but few on the factors of vaginal delivery failure. ${ }^{13}{ }^{15}$ Several studies have found that anxiety and fear about the delivery process increased the risk of EmCS twofold. ${ }^{16}$ Furthermore, advanced age, obesity and overweight are also risk factors for failure of vaginal delivery and EmCS. ${ }^{17}{ }^{18}$ Unfortunately, these single-factor studies do not combine other factors of mother and infant, and cannot quantify the risk of EmCS.

The purpose of this study is to systematically analyze 22 maternal and fetal factors in terms of demographic characteristics of pregnant women, pregnancy history, perinatal complications, neonatal features and labor process, in order to identify the high-risk factors associated with EmCS before delivery. A risk scoring system was then established to quantitatively predict the risk of EmCS during vaginal delivery.

\section{MATERIALS AND METHODS Study population}

In this study we retrospectively analyzed the medical records in the Department of Obstetrics, Maternal and Child Health Hospital of Hubei Province, China. The inclusion and exclusion criteria were as follows. Inclusion criteria: (1) all patients delivered in our hospital from January 1, 2016 to December 31, 2016; (2) gestation age (weeks) <42; (3) vaginal examination was performed before vaginal delivery and there were no abnormalities in pelvic measurements or complications endangering the lives of mothers and fetuses; (4) there was no fetal distress and no obvious headpelvic disproportion before the trial of vaginal delivery. A total of 19,816 cases met the criteria. Exclusion criteria: (1) multiple birth $(\mathrm{n}=402)$; (2) breech position $(\mathrm{n}=810)$ and transverse/oblique position $(\mathrm{n}=161),(3)$ received CS after full-term pregnancy due to severe complications of fetal malformation $(n=20)$; (4) those who failed in vaginal delivery in the external hospital and were transferred to our hospital $(\mathrm{n}=20)$; (5) direct CS with certain indications $(n=8108)$. Thus, a total of 10,295 cases were included in this study. EmCS was defined as a case in which the procedure of vaginal delivery was discontinued due to the occurrence of fetal distress or other reasons. Fetal distress was defined as depletion of oxygen and accumulation of carbon dioxide, leading to a state of 'hypoxia and acidosis' during intrauterine life. Continuous electronic fetal heart rate (FHR) monitoring was performed for each woman during the process of labor to evaluate the status of fetal distress based on a three-tiered system categorization of FHR patterns which was recommended by the American College of Obstetricians and Gynecologists (ACOG). The research protocol for this study was approved by the Medical Ethics Committee of Maternal and Child Health Hospital of Hubei Province. This study was a retrospective study. We only extracted clinically relevant information, did not affect the treatment and health of patients, and the patients' privacy was protected, so written informed consent was not applicable for this study.

\section{Outcome measures}

All perinatal data were extracted from medical records and classified into five items: demographic characteristics of pregnant women (maternal age, height, weight before pregnancy, body mass index (BMI) before pregnancy, weight at delivery, BMI at delivery, gestational age), pregnancy history (gravidity, parity, previous CS), perinatal complications (characters of amniotic fluid, umbilical cord status, hypertensive disorders of pregnancy, low lying placenta, placental abruption, oligohydramnios, hydramnion), neonatal features (birth weight, macrosomia, fetal gender) and labor process (induction of labor, epidural anasthesia). According to the outcome of vaginal delivery, all women were classified into two groups: normal vaginal delivery (NVD) and EmCS. The primary outcome of this study was to identify the possible independent factors associated with the failure of vaginal delivery and to quantify the risk of EmCS.

\section{Statistical analysis}

Statistical analyses were performed using SPSS version 19.0 (SPSS Inc, Chicago, Illinois, USA). Quantitative variables were expressed as mean \pm SD. Qualitative variables were expressed as absolute and relative frequencies. Univariate analysis was performed to explore the relationship between EmCS rate and perinatal factors. In order to find factors independently associated with the risk for EmCS, a multiple logistic regression analysis was performed in a stepwise fashion. Statistical significance was considered to be the case when $\mathrm{p}<0.05$ or if the $95 \%$ CI of odds ratios (OR) did not include 1. In order to better evaluate the risk coefficient in the development of the risk scoring system, the $75 \%$ quantile was chosen as the cut-off value and the integer of the OR value was used as the score for each risk factor.

\section{RESULTS}

\section{Characteristics of study population}

A total of 10,295 women met the inclusion and exclusion criteria, of which $9304(90.37 \%)$ cases were successfully managed with vaginal delivery and 991 (9.63\%) cases were transferred to EmCS during the process of vaginal delivery. There were some differences between the two groups in terms of the demographic characteristics of the pregnant women, pregnancy history, perinatal complications, neonatal features and labor process (table 1). The mean $\pm S D$ age of the pregnant women in the EmCS group $(28.59 \pm 3.22)$ was significantly higher than that in the NVD group $(28.02 \pm 3.53)(\mathrm{p}<0.001)$, and the proportion of women of advanced age was significantly higher in the EmCS group $(5.45 \%)$ than in the NVD group $(4.61 \%)$ $(\mathrm{p}<0.001)$. There was no significant difference in gestational age and maternal height between the two groups 
Original research

Table 1 Characteristics of study population

\begin{tabular}{|c|c|c|c|c|}
\hline \multirow[b]{2}{*}{ Variable } & \multirow{2}{*}{$\begin{array}{l}\text { Study population } \\
(\mathrm{n}=10,295)(\%)\end{array}$} & \multicolumn{3}{|l|}{ Groups } \\
\hline & & NVD (n=9304) (\%) & EmCS $(n=991)(\%)$ & P value* \\
\hline \multicolumn{5}{|c|}{ Demographic characteristics of pregnant women } \\
\hline Mean age (years) & $28.08 \pm 3.51$ & $28.02 \pm 3.53$ & $28.59 \pm 3.22$ & $<0.001$ \\
\hline \multicolumn{5}{|l|}{ Age categories (years) } \\
\hline$<25$ & $2121(20.60)$ & $1986(21.35)$ & $135(13.62)$ & $<0.001$ \\
\hline $25-29$ & $5179(47.30)$ & $4649(49.96)$ & $530(53.48)$ & \\
\hline $30-35$ & $2512(24.40)$ & $2240(24.08)$ & $272(27.45)$ & \\
\hline$\geq 35$ & $483(4.70)$ & $429(4.61)$ & $54(5.45)$ & \\
\hline Height $(\mathrm{cm})$ & $161.6 \pm 0.046$ & $161.6 \pm 0.045$ & $161.8 \pm 0.048$ & 0.313 \\
\hline Gestational age (weeks) & $39.41 \pm 1.41$ & $39.41 \pm 1.43$ & $39.43 \pm 1.28$ & 0.555 \\
\hline Weight before pregnancy $(\mathrm{kg})$ & $51.35 \pm 5.41$ & $51.17 \pm 5.29$ & $53.03 \pm 6.19$ & $<0.001$ \\
\hline BMI before pregnancy $\left(\mathrm{kg} / \mathrm{m}^{2}\right)$ & $19.67 \pm 2.10$ & $19.61 \pm 2.03$ & $20.31 \pm 2.58$ & $<0.001$ \\
\hline Weight at delivery (kg) & $68.71 \pm 8.18$ & $68.48 \pm 8.06$ & $70.89 \pm 8.88$ & $<0.001$ \\
\hline $\mathrm{BMI}$ at delivery $\left(\mathrm{kg} / \mathrm{m}^{2}\right)$ & $26.30 \pm 2.92$ & $26.21 \pm 2.83$ & $27.13 \pm 3.56$ & $<0.001$ \\
\hline \multicolumn{5}{|l|}{ Pregnancy history } \\
\hline \multicolumn{5}{|l|}{ Gravidity } \\
\hline Primigravidity & $6165(59.88)$ & $5512(59.24)$ & $653(65.89)$ & $<0.001$ \\
\hline Multigravidas & $4130(40.12)$ & $3792(40.76)$ & $338(34.11)$ & \\
\hline \multicolumn{5}{|l|}{ Parity } \\
\hline Nulliparous & $8775(85.24)$ & $7830(84.16)$ & $946(95.46)$ & $<0.001$ \\
\hline Multiparous & $1519(14.76)$ & $1474(15.84)$ & $45(4.54)$ & \\
\hline \multicolumn{5}{|l|}{ Previous cesarean section } \\
\hline Yes & $40(0.39)$ & $36(0.39)$ & $4(0.39)$ & 0.936 \\
\hline No & 10255 (99.61) & $9268(99.61)$ & 987 (99.61) & \\
\hline \multicolumn{5}{|l|}{ Perinatal complications } \\
\hline \multicolumn{5}{|l|}{ Characters of amniotic fluid } \\
\hline Clear & 7459 (72.45) & $6977(74.99)$ & $482(48.64)$ & $<0.001$ \\
\hline Stage I & $239(2.33)$ & $214(2.30)$ & $25(2.52)$ & \\
\hline Stage II & $194(1.88)$ & $185(1.99)$ & $9(0.91)$ & \\
\hline Stage III/bloody & $2403(23.34)$ & $1928(20.72)$ & $475(47.93)$ & \\
\hline \multicolumn{5}{|l|}{ Umbilical cord status } \\
\hline Normal & $6452(62.67)$ & $5928(63.71)$ & $524(52.88)$ & $<0.001$ \\
\hline Cord entanglement & 3547 (34.45) & $3136(33.71)$ & $411(41.47)$ & \\
\hline Torsion of umbilical cord & $296(2.88)$ & $240(2.58)$ & $56(5.65)$ & \\
\hline \multicolumn{5}{|l|}{$\mathrm{HDP}^{*}$} \\
\hline Yes & $429(4.17)$ & $362(3.89)$ & $67(6.76)$ & $<0.001$ \\
\hline No & $9866(95.83)$ & $8942(96.11)$ & 924 (93.24) & \\
\hline \multicolumn{5}{|l|}{ Low lying placenta } \\
\hline Yes & $40(0.39)$ & $38(0.41)$ & $2(0.20)$ & 0.320 \\
\hline No & $10255(99.61)$ & 9266 (99.59) & $989(99.80)$ & \\
\hline \multicolumn{5}{|l|}{ Placental abruption } \\
\hline Yes & $40(0.39)$ & $36(0.39)$ & $4(0.40)$ & 0.936 \\
\hline No & $10255(99.61)$ & $9268(99.61)$ & $987(99.60)$ & \\
\hline \multicolumn{5}{|l|}{ Oligohydramnios } \\
\hline Yes & $72(0.70)$ & $40(0.43)$ & $32(3.23)$ & $<0.001$ \\
\hline No & $10223(99.3)$ & $9264(99.57)$ & 959 (96.77) & \\
\hline \multicolumn{5}{|l|}{ Hydramnion } \\
\hline Yes & $50(0.49)$ & $36(0.39)$ & $14(1.41)$ & $<0.001$ \\
\hline No & $10245(99.51)$ & $9268(99.61)$ & 977 (98.59) & \\
\hline \multicolumn{5}{|l|}{ Neonatal features } \\
\hline Birth weight (g) & $3293.78 \pm 415.51$ & $3275.88 \pm 413.38$ & $3461.84 \pm 397.55$ & $<0.001$ \\
\hline \multicolumn{5}{|l|}{ Neonatal weight (g) } \\
\hline$<2500$ & $260(2.53)$ & $252(2.71)$ & $8(0.81)$ & $<0.001$ \\
\hline $2500-4000$ & 9581 (93.06) & $8698(93.48)$ & $883(89.10)$ & \\
\hline
\end{tabular}




\begin{tabular}{|c|c|c|c|c|}
\hline \multirow[b]{2}{*}{ Variable } & \multirow{2}{*}{$\begin{array}{l}\text { Study population } \\
(\mathrm{n}=10,295)(\%)\end{array}$} & \multicolumn{3}{|l|}{ Groups } \\
\hline & & NVD (n=9304) (\%) & EmCS (n=991) (\%) & P value* \\
\hline$\geq 4000$ (macrosomia) & $454(4.41)$ & $354(3.81)$ & $100(10.09)$ & \\
\hline \multicolumn{5}{|l|}{ Gender } \\
\hline Male & $5372(52.18)$ & $4806(51.66)$ & $566(57.11)$ & 0.001 \\
\hline Female & $4923(47.82)$ & $4498(48.34)$ & $425(42.89)$ & \\
\hline \multicolumn{5}{|l|}{ Labor process } \\
\hline \multicolumn{5}{|l|}{ Induction of labor } \\
\hline Yes & $1180(11.46)$ & $822(8.83)$ & $358(36.13)$ & $<0.001$ \\
\hline No & 9115 (88.54) & $8482(91.17)$ & $633(63.87)$ & \\
\hline \multicolumn{5}{|l|}{ Epidural anesthesia } \\
\hline Yes & 6485 (62.99) & $5855(62.92)$ & $630(63.57)$ & 0.052 \\
\hline No & 3810 (37.01) & 3449 (37.08) & 361 (36.43) & \\
\hline
\end{tabular}

*Two-sided $\mathrm{p}<0.05$ was considered statistically significant, and the bold typeface shows the significant data.

BMI, body mass index; EmCS, emergency cesarean section; HDP, hypertensive disorders of pregnancy; NVD, normal vaginal delivery.

( $p>0.05$ for all). Compared with the NVD group, maternal weight before pregnancy, maternal BMI before pregnancy, maternal weight at delivery and maternal BMI at delivery in the EmCS group were significantly higher $(\mathrm{p}<0.05$ for all).

The proportion of the pregnant women who conceived and gave birth for the first time in the EmCS group was higher than that in the NVD group $(\mathrm{p}<0.01)$. There was no difference in the proportion of pregnant women with previous CS between the two groups $(\mathrm{p}=0.936)$. Compared with the NVD group, pregnant women with abnormal amniotic fluid characteristics, abnormal quantity of amniotic fluid (oligohydramnios, hydramnion), abnormal umbilical cord status (normal, cord entanglement, torsion) and hypertensive disorders of pregnancy (HDP) was significantly higher in the EmCS group ( $p<0.05$ for all). The differences in the proportion of pregnant women with low lying placenta and placental abruption between the two groups were not statistically significant ( $p>0.05$ for all).

In the EmCS group, the proportion of male infants $(57.11 \%)$ was significantly higher than in the NVD group $(51.66 \%)$, the weight of neonates in the EmCS group $(3461.84 \pm 397.55)$ was significantly higher than in the NVD group (3275.88 \pm 413.38 ), and the proportion of macrosomia in the EmCS group (10.09\%) was significantly higher than in the NVD group $(3.81 \%)(\mathrm{p}<0.001)$. In addition, the proportion of pregnant women receiving induction of labor in the EmCS group (36.13\%) was higher than that in the NVD group (8.83\%), and the difference was statistically significant $(p<0.001)$. There was no significant difference in the proportion of pregnant women receiving epidural anesthesia between the two groups $(p=0.052)$. Altogether, differences were observed in 17 variables between the two groups.

\section{Analysis of causes of EmCS}

Among 991 pregnant women who received EmCS, the major direct causes were fetal distress $(n=666,67.21 \%)$, persistent occipital transverse position or occipital posterior position $(\mathrm{n}=148,14.93 \%)$, and relative cephalopelvic disproportion $(\mathrm{n}=81,8.17 \%)$. Sixty-four $(6.46 \%)$ women underwent EmCS because of their unwillingness to cooperate with vaginal delivery due to personal factors. In particular, 11
(1.11\%) pregnant women suffered from prenatal hemorrhage during delivery and EmCS was performed to ensure the safety of mothers and infants (table 2).

In the course of vaginal delivery, the cervical dilatation of five women was $0 \mathrm{~cm}$ and about 10 women had EmCS even though the cervical dilatation was $10 \mathrm{~cm}$. Of the 991 cases, the mean cervical dilatation was $3.11 \pm 1.92 \mathrm{~cm}$ (median $2.5 \mathrm{~cm})$. There were $518(52.27 \%)$ parturients with cervical dilatation less than $3 \mathrm{~cm}$ in whom EmCS was performed. The cervical dilatation was significantly higher in women who underwent EmCS for abnormal fetal position $(\mathrm{p}<0.001)$.

\section{Univariate and multivariate analysis of the risk of EmCS}

Variables with differences between the NVD and EmCS groups were included in the univariate analysis. The results showed that the risk of EmCS increased if the pregnant woman had one of the following conditions: maternal age $\geq 30$ years, BMI $\geq 20.5$ before pregnancy, BMI $\geq 28$ at delivery, nulliparous, abnormal characteristics of amniotic fluid, abnormal umbilical cord, HDP, abnormal quantity of amniotic fluid, neonatal weight $>3550 \mathrm{~g}$, male newborn and need to induce labor $(\mathrm{p}<0.05$ for all). However,

Table 2 Reasons for emergency cesarean section

\begin{tabular}{llll}
\hline Reasons & Value & P value & $\begin{array}{l}\text { Cervical } \\
\text { dilatation } \\
(\mathrm{cm})^{*}\end{array}$ \\
\hline Fetal distress & $666(67.21)$ & $<0.001$ & $2.85 \pm 1.63$ \\
Abnormal fetal position & $148(14.93)$ & & $4.93 \pm 2.38$ \\
$\begin{array}{l}\text { Relative cephalopelvic } \\
\text { disproportion }\end{array}$ & $81(8.17)$ & & $2.71 \pm 1.73$ \\
Social factors & $64(6.46)$ & & $2.16 \pm 1.30$ \\
Others $\dagger$ & $21(2.12)$ & & $2.83 \pm 1.93$ \\
Antepartum hemorrhage & $11(1.11)$ & & $2.82 \pm 1.47$ \\
\hline
\end{tabular}

${ }^{*}$ Compared with other groups, the cervical dilatation was significantly higher in women who received EmCS for abnormal fetal position ( $p<0.001$ for all). tOthers included pathologic retraction rings in 6 cases $(0.61 \%)$, preeclampsia in $9(0.91 \%)$, threatened uterine rupture in $5(0.50 \%)$ and presentation of umbilical cord in 1 case $(0.10 \%)$. 
Table 3 Univariate and multivariate analyses of factors associated with EmCS

\begin{tabular}{|c|c|c|c|c|c|}
\hline \multirow[b]{2}{*}{ Variables } & \multirow[b]{2}{*}{$\mathrm{N}(\%)$} & \multicolumn{2}{|l|}{ Univariate } & \multicolumn{2}{|l|}{ Multivariate } \\
\hline & & OR $(95 \% \mathrm{Cl})$ & $P$ value & OR $(95 \% \mathrm{Cl})$ & $P$ value \\
\hline \multicolumn{6}{|c|}{ Demographic characteristics } \\
\hline \multicolumn{6}{|c|}{ Age (years) } \\
\hline$<30$ & $7300(70.91)$ & Ref & & Ref & \\
\hline$\geq 30$ & $2995(29.09)$ & 1.129 (1.060 to 1.402$)$ & 0.006 & 1.619 (1.381 to 1.898$)$ & $<0.001$ \\
\hline \multicolumn{6}{|c|}{ BMI before pregnancy $\left(\mathrm{kg} / \mathrm{m}^{2}\right)$} \\
\hline$<20.5$ & $7793(75.70)$ & Ref & & Ref & \\
\hline$\geq 20.5$ & $2502(24.30)$ & 1.936 (1.687 to 2.23$)$ & $<0.001$ & 1.868 (1.576 to 2.214$)$ & $<0.001$ \\
\hline \multicolumn{6}{|c|}{ BMI at delivery $\left(\mathrm{kg} / \mathrm{m}^{2}\right)$} \\
\hline$<28$ & $7713(74.92)$ & Ref & & Ref & \\
\hline$\geq 28$ & $2582(25.08)$ & 1.765 (1.537 to 2.027$)$ & $<0.001$ & 1.244 (1.048 to 1.478$)$ & 0.016 \\
\hline \multicolumn{6}{|c|}{ Pregnancy history } \\
\hline \multicolumn{6}{|c|}{ Gravidity } \\
\hline Primigravidity & $6165(59.88)$ & Ref & & Ref & \\
\hline Multigravidity & $4130(40.12)$ & 0.752 (0.656 to 0.863$)$ & $<0.001$ & 0.918 (0.783 to 1.077 ) & 0.235 \\
\hline Parity & & Ref & & Ref & \\
\hline Multiparous & $1519(14.76)$ & Ref & & & \\
\hline Nulliparous & $8775(85.24)$ & 3.957 (2.292 to 5.364$)$ & $<0.001$ & 4.336 (3.074 to 6.115$)$ & $<0.001$ \\
\hline \multicolumn{6}{|c|}{ Perinatal complications } \\
\hline \multicolumn{6}{|c|}{ Characters of amniotic fluid } \\
\hline Clear & $7459(72.45)$ & Ref & & Ref & \\
\hline Abnormal* & $2836(27.55)$ & 3.166 (2.772 to 3.617$)$ & $<0.001$ & 3.126 (2.708 to 3.608$)$ & $<0.001$ \\
\hline \multicolumn{6}{|c|}{ Umbilical cord } \\
\hline Normal & $6452(62.67)$ & Ref & & Ref & \\
\hline Abnormalt & $3843(37.3)$ & 1.565 (1.372 to 1.785$)$ & $<0.001$ & 1.414 (1.225 to 1.632$)$ & $<0.001$ \\
\hline \multicolumn{6}{|l|}{ HDP } \\
\hline No & $9866(95.83)$ & Ref & & Ref & \\
\hline Yes & $429(4.17)$ & 1.791 (1.368 to 2.345$)$ & $<0.001$ & 1.372 (1.012 to 1.860$)$ & 0.050 \\
\hline \multicolumn{6}{|c|}{ Abnormal quantity of amniotic fluid } \\
\hline No & $10173(98.81)$ & Ref & & & \\
\hline Yes‡ & $122(1.19)$ & 5.910 (4.074 to 8.576$)$ & $<0.001$ & 6.867 (4.442 to 10.618$)$ & $<0.001$ \\
\hline \multicolumn{6}{|c|}{ Neonatal features } \\
\hline \multicolumn{6}{|c|}{ Neonatal weight (g) } \\
\hline$<3550$ & $7454(72.40)$ & Ref & & Ref & \\
\hline$\geq 3550$ & $2841(27.60)$ & 2.181 (1.908 to 2.494$)$ & $<0.001$ & 2.070 (1.786 to 2.400$)$ & $<0.001$ \\
\hline \multicolumn{6}{|l|}{ Gender } \\
\hline Female & $4923(47.82)$ & Ref & & Ref & \\
\hline Male & $5372(52.18)$ & $1.246(1.092$ to 1.423$)$ & 0.001 & $1.216(1.052-1.404)$ & 0.008 \\
\hline \multicolumn{6}{|l|}{ Labor process } \\
\hline \multicolumn{6}{|c|}{ Induction of labor } \\
\hline No & $9115(88.54)$ & Ref & & Ref & \\
\hline Yes & $1180(11.46)$ & 5.836 (5.033 to 6.767$)$ & $<0.001$ & 5.300 (4.514 to 6.224$)$ & $<0.001$ \\
\hline
\end{tabular}

*Abnormal amniotic fluid character included stage I-III, bloody.

tAbnomal umbilical cord included cord entanglement and torsion of the umbilical cord.

$¥$ Abnormal quantity of amniotic fluid includes oligohydramnios and hydramnion.

BMI, body mass index; HDP, hypertensive disorders of pregnancy; Ref, reference category.

multigravidity (OR $0.752,95 \% \mathrm{CI} \quad 0.656$ to 0.863 ) decreased the risk of EmCS (table 3).

By incorporating the above 12 meaningful indicators into further multivariate analysis, it was found that gravidity was not an independent risk factor for EmCS $(p=0.235)$ and the significance of HDP was marginal $(p=0.50)$. The risk of EmCS in pregnant women with abnormal amniotic fluid quantity was more than six times higher than that in those with a normal quantity of amniotic fluid (OR 6.867,
95\% CI 4.442 to $10.618, \mathrm{p}<0.001)$. The risk of EmCS in nulliparous women was about four times higher than in multiparous women (OR 4.336, 95\% CI 3.074 to 6.115 , $\mathrm{p}<0.001$ ), the risk of EmCS in pregnant women who needed induction of labor was more than five times higher than in pregnant women who had spontaneous onset (OR 5.300, 95\% CI 4.514 to $6.224, \mathrm{p}<0.001$ ), while the risk of EmCS in pregnant women with abnormal characters of amniotic fluid was three times higher than in pregnant 


\begin{tabular}{|c|c|c|c|c|c|c|}
\hline EmCS risk scoring system (scores ) & N (\%) & $\operatorname{NVD}(n, \%)$ & $\operatorname{EmCS}(n, \%)$ & $P$ value* & Or $(95 \% \mathrm{Cl})$ & $P$ valuet \\
\hline Grade 1 (0-3 points) & $919(8.93)$ & $907(9.75)$ & $12(1.21)$ & $<0.001$ & Ref & \\
\hline Grade 2 (4-5 points) & $3389(32.92)$ & $3302(35.49)$ & $87(8.78)$ & & 1.991 (1.084 to 3.658$)$ & 0.026 \\
\hline Grade 3 (6-7 points) & $2605(25.30)$ & $2453(26.37)$ & $152(15.34)$ & & 4.684 (2.589 to 8.471$)$ & $<0.001$ \\
\hline Grade 4 (8-9 points) & $1686(16.38)$ & $1451(15.59)$ & $235(23.71)$ & & 12.241 (6.813 to 21.994$)$ & $<0.001$ \\
\hline Grade 5 (10-11 points) & $938(9.11)$ & $734(7.89)$ & $204(20.58)$ & & 21.007 (11.641 to 37.906$)$ & $<0.001$ \\
\hline Grade 6 ( $\geq 12$ points) & $758(7.36)$ & $457(4.91)$ & $301(30.38)$ & & 49.782 (27.656 to 89.611$)$ & $<0.001$ \\
\hline
\end{tabular}

${ }^{*}$ Chi square tests were used.

tLogistic regression analysis was used.

EmCS, emergency cesarean section; HDP, hypertensive disorders of pregnancy; NVD, normal vaginal delivery; Ref, reference category.

women with clear amniotic fluid (OR 3.126, 95\% CI 2.708 to $3.608, \mathrm{p}<0.001$ ).

\section{Development of EmCS risk scoring system}

In order to effectively identify pregnant women with a high risk of EmCS, we further scored the abovementioned independent risk factors according to OR value. Briefly, women who had a risk factor with OR value between 1 and 2 were scored as 1 point, women with a risk factor with OR value between 2 and 3 were scored as 2 points, and so on. The score was 0 if there was no risk factor. Considering that it is illegal to differentiate the sex of newborns before delivery, and the significance of HDP in this study was limited, only nine factors were included and scored as follows: maternal age $\geq 30$ years ( 1 point), BMI $\geq 20.5$ before pregnancy ( 1 point), BMI $\geq 28$ before delivery ( 1 point), nulliparous ( 4 points), abnormal characters of amniotic fluid (3 points), abnormal umbilical cord (1 point), abnormal quantity of amniotic fluid ( 6 points), neonatal weight $\geq 3550 \mathrm{~g}$ ( 2 points) and induction of labor (5 points). Each woman scored the sum of the nine factors ( $0-24$ points). The results showed that all women in this study had scores ranging from 0 to 22. According to the proportion of pregnant women with different scores in the EmCS group, the EmCS risk scoring system was further established: scores of $0-3$ were categorized as grade 1 , scores of $4-5$ were grade 2 , scores of $6-7$ were grade 3 , scores of $8-9$ were grade 4 , scores of $10-11$ were grade 5 and scores of 12 points and above were grade 6 (table 4).

The rate of EmCS was 1.30\%, 2.57\%, 5.83\%, 13.94\%, $21.75 \%$ and $39.71 \%$ in patients with grade $1,2,3,4,5$ and 6 , respectively. The difference was statistically significant $(p<0.001)$. Nearly $70 \%$ of pregnant women in the NVD group were grades $1-3$, while over $74 \%$ of pregnant women in the EmCS group were grades 4-6; the difference was statistically significant $(\mathrm{p}<0.001)$. When the risk of the pregnant women was lower than or equal to grade 3, the rate of EmCS was lower than that of the study population $(9.63 \%)$. Therefore, pregnant women with a risk score above grade 4 need to be particularly vigilant and may need EmCS during the vaginal delivery process. Compared with pregnant women in grade 1, the risk of EmCS in pregnant women increased significantly with the increase in grade, with OR $(95 \% \mathrm{CI})$ values of 1.991 (1.084-3.658), 4.684 (2.589-8.471), 12.241 (6.813-21.994), 21.007 (11.641$37.906)$ and $49.782(27.656-89.611)$ for grades $1,2,3$, 4,5 and 6, respectively. The area under the curve of the risk scoring system was 0.787 (95\% CI 0.772 to 0.801 , $\mathrm{p}<0.001$ ), which was more valuable than any other single risk factor, indicating that the regression model of the risk factors had a good predictive ability (figure 1).

\section{DISCUSSION}

This study aimed to answer the following questions: (1) Do the maternal and fetal factors differ in NVD and EmCS groups? (2) To what extent do maternal and fetal perinatal factors affect EmCS? (3) Is there a simple and feasible model based on measurable and repeatable maternal and fetal factors that can predict the risk of EmCS?

Globally, the CS rate is rising and medically unnecessary CSs are prevalent. ${ }^{19}{ }^{20}$ Increased maternal obesity, widespread assisted reproductive technology, cultural and social elements are also contributing factors. ${ }^{21} 22$ However, there are some special cases such as those who fail in the course of attempting vaginal delivery and then must receive EmCS to terminate the delivery. How to identify these mothers and perform emergency surgery in time is very important to ensure the safety of mothers and infants. ${ }^{23}$ In this study, our findings showed that $9.63 \%$ of pregnant women had EmCS. This result is lower than that of other researchs. ${ }^{24}$ To answer the first question, we analyzed the differences in more than 20 maternal and infant characteristics between the two groups. The results showed that there was no difference in the proportion of pregnant women with low lying placenta and placental abruption beween the NVD

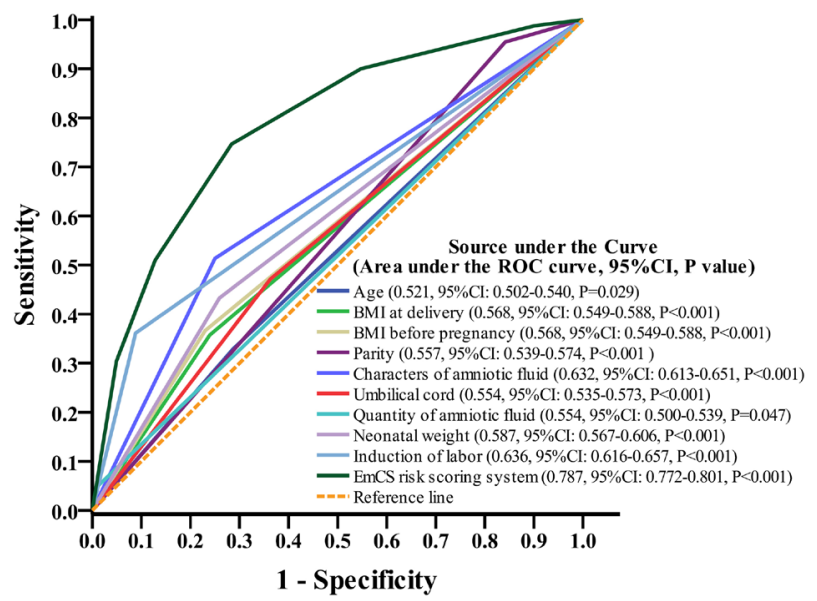

Figure 1 Maternal and fetal factors-based risk scoring system performed well in predicting the risk of emergency cesarean section (EmCS) of pregnant women compared with other factors. 
and EmSC groups. Studies have shown that only patients with low lying placenta who have a history of hospitalization due to vaginal bleeding and whose cervix continues to shorten have an increased risk of EmCS. ${ }^{25}$ In addition, our results suggested that epidural anesthesia during delivery does not reduce productivity and lead to EmCS. In fact, some studies have shown that anesthetic leads to a better analgesic satisfaction without adverse effects on uterine electromyographic activities or obstetric outcomes during labor. ${ }^{26}{ }^{27}$ We can therefore use labor analgesia in more patients to relieve pain. As we know, childbirth may cause the most severe pain some women experience in their lifetime, and some women finally choose EmCS because they cannot tolerate the pain. ${ }^{26}$

The influence of the abovementioned maternal and fetal factors on the risk of EmCS was further analyzed to answer the second question. Univariate analysis found that 12 factors were associated with the risk of EmCS, including age, pre-pregnancy BMI, BMI at delivery, gravidity, parity, fetal weight and gender. However, multivariate analysis found that gravidity was not an independent risk factor and the impact of HDP was only marginally significant. These results are similar to other studies. ${ }^{1728-30}$ It was noteworothy that an abnormal quantity of amniotic fluid was the greatest risk factor affecting EmCS, followed by spontaneous seizure or induction of labor. Although induction of labor is the most common intervention in obstetrics, it actually reflects the underlying problems of pregnant women with an uncomplicated singleton pregnancy in the onset of labor and subsequent spontaneous vaginal delivery. ${ }^{31} \mathrm{It}$ has been documented that, compared with spontaneous onset of delivery, induction of labor is associated with an increased risk for EmCS among both nulliparous and multiparous women. ${ }^{32}$ However, a recent clinical trial showed that, for certain women with large-for-date fetuses, labor would not increase the rate of EmCS and would instead have certain benefits in reducing shoulder dystocia and increase the success rate of vaginal delivery. ${ }^{33}$ Interestingly, we found that when the fetus was male, women were more likely to have EmCS. Similarly, other studies also demonstrated that male babies were more likely to be delivered by instrumental delivery, as well as by EmCS for failure to progress and fetal distress, even after adjusting for birth weight. ${ }^{34}{ }^{35}$ It is suggested that there is a different feto-placental response to the induction of the labor process between the fetal genders, which could explain the higher failure rates in male fetuses. ${ }^{36}$

Although some studies suggest that mental health status can predict delivery outcomes, ${ }^{14}$ there is still a lack of an independent scoring system with strong objectivity and good repeatability for Chinese women. Thus, we discussed the third issue by incorporating these maternal and fetal factors, aiming to quantify the risk for each factor and identify high-risk groups of pregnant women. Because it is illegal to identify the sex of the fetus before delivery, this study included nine factors that could be determined before delivery, and a risk scoring system for EmCS has been established. The results showed that this system can effectively identify women with a high risk of EmCS, and was superior to any single factor in prediction. In clinical circumstances, the information of maternal age, BMI before pregnancy, BMI at delivery and childbirth history can be obtained after admission, and other factors including the weight of the newborns, the quantity of amniotic fluid and umbilical cord status can be evaluated by ultrasound before delivery. Thus, this risk scoring system is simple, easy to operate and has good repeatability in clinical practice. If the score is too high, we should pay close attention to the situation of mothers and babies during childbirth. The limitation of this study was that it was a retrospectively designed study, and the conclusions were only based on the results of the present study. The clinical significance shuld be tested and validated in a further prospective study.

\section{CONCLUSION}

This study analyzed the differences in 22 maternal and fetal factors between NVD and EmCS groups, then identified nine factors (maternal age $\geq 30, \mathrm{BMI} \geq 20.5$ before pregnancy, $\mathrm{BMI} \geq 28$ at delivery, nulliparous, abnormal characteristics of the amniotic fluid, abnormal umbilical cord, abnormal quantity of amniotic fluid, neonatal weight $\geq 3550 \mathrm{~g}$, and induction of labor) that were associated with a high risk of EmCS. An effective risk scoring system based on the nine factors has been developed to quantitatively assess the risk of EmCS and classify women into different risk groups from the very beginning of labor. The practical value will be determined in further prospective observation studies.

Contributors PG: data collection, data analysis, manuscript writing. FT: data collection. GS: data analysis. WR: project development, manuscript writing.

Funding This work was supported by Scientific Research Projects of Hubei Provincial Maternity \& Children Hospital (no. 20927006) and Epidemiological study of hypertensive disease in pregnancy and pregnancy outcome of mother and child in Hubei province (WJ2018H0147).

Competing interests None declared.

Patient consent for publication Not required.

Provenance and peer review Not commissioned; externally peer reviewed.

Data availability statement All data relevant to the study are included in the article or uploaded as supplementary information.

Open access This is an open access article distributed in accordance with the Creative Commons Attribution Non Commercial (CC BY-NC 4.0) license, which permits others to distribute, remix, adapt, build upon this work noncommercially, and license their derivative works on different terms, provided the original work is properly cited, an indication of whether changes were made, and the use is non-commercial. See: http://creativecommons.org/ licenses/by-nc/4.0/.

\section{ORCID iD}

Wei Ren http://orcid.org/0000-0003-2573-8469

\section{REFERENCES}

1 Li H-T, Luo S, Trasande L, et al. Geographic variations and temporal trends in cesarean delivery rates in China, 2008-2014. JAMA 2017;317:69-76.

2 Hamilton BE, Martin JA, Osterman MJK, et al. Births: preliminary data for 2014. Natl Vital Stat Rep 2015;64:1-19.

3 Anon. Appropriate technology for birth. Lancet 1985;2:436-7.

4 Betran AP, Torloni MR, Zhang JJ, et al. WHO statement on caesarean section rates. BJOG 2016;123:667-70.

5 Harrison MS, Pasha O, Saleem S, et al. A prospective study of maternal, fetal and neonatal outcomes in the setting of cesarean section in low- and middleincome countries. Acta Obstet Gynecol Scand 2017;96:410-20.

6 Kupari M, Talola N, Luukkaala T, et al. Does an increased cesarean section rate improve neonatal outcome in term pregnancies? Arch Gynecol Obstet 2016;294:41-6

7 Black M, Bhattacharya S, Philip S, et al. Planned cesarean delivery at term and adverse outcomes in childhood health. JAMA 2015;314:2271-9. 
8 Ye J, Zhang J, Mikolajczyk R, et al. Association between rates of caesarean section and maternal and neonatal mortality in the 21st century: a worldwide population-based ecological study with longitudinal data. BJOG 2016;123:745-53.

9 Gosset M, llenko A, Bouyou J, et al. Emergency caesarean section. J Visc Surg 2017:154:47-50

10 Lumbiganon P, Laopaiboon M, Gülmezoglu AM, et al. Method of delivery and pregnancy outcomes in Asia: the WHO global survey on maternal and perinatal health 2007-08. Lancet 2010;375:490-9.

11 David M, Scherer KA, Henrich W, et al. Does an immigrant background affect the indication, incidence or outcome of emergency cesarean section? Results of the prospective data collection of 111 births. Geburtshilfe Frauenheilkd 2018;78:167-72.

12 Ryding EL, Wijma K, Wijma B. Psychological impact of emergency cesarean section in comparison with elective cesarean section, instrumental and normal vaginal delivery. J Psychosom Obstet Gynaecol 1998;19:135-44.

13 Yang X-J, Sun S-S. Comparison of maternal and fetal complications in elective and emergency cesarean section: a systematic review and meta-analysis. Arch Gynecol Obstet 2017;296:503-12.

14 Wangel AM, Molin J, Ostman M, et al. Emergency cesarean sections can be predicted by markers for stress, worry and sleep disturbances in first-time mothers. Acta Obstet Gynecol Scandi 2011;90:238-44.

15 Herstad L, Klungsøyr K, Skjærven R, et al. Elective cesarean section or not? Maternal age and risk of adverse outcomes at term: a population-based registry study of low-risk primiparous women. BMC Pregnancy Childbirth 2016;16:230

16 Ryding EL, Wijma B, Wijma K, et al. Fear of childbirth during pregnancy may increase the risk of emergency cesarean section. Acta Obstet Gynecol Scand 1998;77:542-7

17 Kim S-Y, Park J-Y, Bak S-E, et al. Effect of maternal age on emergency cesarean section. J Matern Fetal Neonatal Med 2019:33:1-8.

18 Jang DG, Jo YS, Lee GSR. Effect of pre-pregnancy body mass index and weight gain during pregnancy on the risk of emergency cesarean section in nullipara. Arch Gynecol Obstet 2011;284:1389-97.

19 Mylonas I, Friese K. Indications for and risks of elective cesarean section. Dtsche Arztebl Int 2015;112:489-95.

20 Vogel JP, Betrán AP, Vindevoghel N, et al. Use of the Robson classification to assess caesarean section trends in 21 countries: a secondary analysis of two WHO multicountry surveys. Lancet Glob Health 2015;3:e260-70.

21 Betran AP, Torloni MR, Zhang J, et al. What is the optimal rate of caesarean section at population level? A systematic review of ecologic studies. Reprod Health 2015:12:57.
22 Miller S, Abalos E, Chamillard M, et al. Beyond too little, too late and too much, too soon: a pathway towards evidence-based, respectful maternity care worldwide. Lancet 2016;388:2176-92.

23 Heller G, Bauer E, Schill S, et al. Decision-to-delivery time and perinatal complications in emergency cesarean section. Dtsche Arzteb/ Int 2017;114:589-96.

24 Muto H, Ishii K, Nakano T, et al. Rate of intrapartum cesarean section and related factors in older nulliparous women at term. J Obstet Gynaecol Res 2018;44:217-22

25 Shin JE, Shin JC, Lee Y, et al. Serial change in cervical length for the prediction of emergency cesarean section in placenta previa. PLoS One 2016;11:e0149036.

26 Sng BL, Zeng Y, de Souza NNA, et al. Automated mandatory bolus versus basal infusion for maintenance of epidural analgesia in labour. Cochrane Database Syst Rev 2018;5:CD011344.

27 Qian X, Wang Q, Ou X, et al. Effects of ropivacaine in patient-controlled epidural analgesia on uterine electromyographic activities during labor. Biomed Res Int 2018:2018:7162865

28 Papoutsis D, Antonakou A, Gornall A, et al. The SaTH risk-assessment tool for the prediction of emergency cesarean section in women having induction of labor for all indications: a large-cohort based study. Arch Gynecol Obstet 2017:295:59-66.

29 Danielsson KC, Borthen I, Gilhus NE, et al. The effect of parity on risk of complications in pregnant women with epilepsy: a population-based cohort study. Acta Obstet Gyneco/ Scand 201810.1111/aogs.13360. [Epub ahead of print: 02 May 2018].

30 Trojner-Bregar A, Blickstein I, Lucovnik M, et al. The relationship between cesarean section rate in term singleton pregnancies, maternal weight, and weight gain during pregnancy. J Perinat Med 2016;44:393-6.

31 Saccone G, Berghella V. Induction of labor at full term in uncomplicated singleton gestations: a systematic review and metaanalysis of randomized controlled trials. Am J Obstet Gynecol 2015;213:629-36.

32 Thorsell M, Lyrenas S, Andolf $\mathrm{E}$, et al. Induction of labor and the risk for emergency cesarean section in nulliparous and multiparous women. Acta Obstet Gynecol Scand 2011;90:1094-9.

33 Boulvain M, Senat M-V, Perrotin F, et al. Induction of labour versus expectant management for large-for-date fetuses: a randomised controlled trial. The Lancet 2015;385:2600-5.

34 Dunn L, Prior T, Greer R, et al. Gender specific intrapartum and neonatal outcomes for term babies. Eur J Obstet Gynecol Reprod Biol 2015;185:19-22.

35 Liu Y, Li G, Zhang W. Effect of fetal gender on pregnancy outcomes in northern China. J Matern Fetal Neonatal Med 2017:30:858-63.

36 Torricelli M, Voltolini C, Vellucci FL, et al. Fetal gender effects on induction of labor in postdate pregnancies. Reprod Sci 2013;20:670-4. 